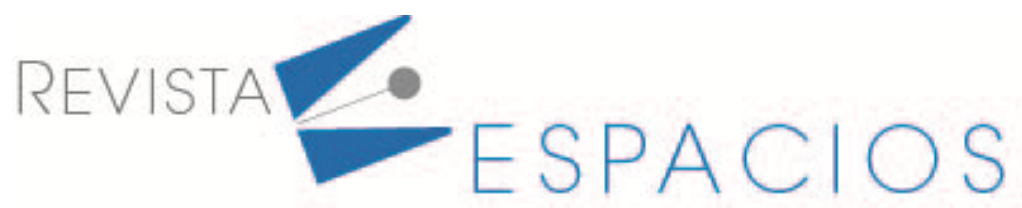

\title{
Inspección de accesibilidad mínima sobre el portal de turismo del Instituto de Cultura y Turismo de Bolívar- Colombia
}

\section{Minimum accessibility inspection on the tourism website of the Institute of Culture and Tourism of Bolívar - Colombia}

\author{
CHANCHÍ, Gabriel E. ${ }^{1}$ \\ OSPINA, Manuel A. ${ }^{2}$ \\ PÉREZ, Jorge L. ${ }^{3}$ \\ Resumen \\ Se realizó una inspección de accesibilidad sobre un portal web de turismo, teniendo en cuenta los cuatro \\ principios de la norma NTC 5854 además de las pautas del nivel de accesibilidad mínima (conformidad \\ A) asociadas a dichos principios. Para el desarrollo de la inspección, se definieron un conjunto de \\ criterios de verificación de accesibilidad mínima desarrollandose un aplicativo que permitió realizar la \\ evaluación de los criterios definidos y así obtener los resultados estadísticos y gráficos de la evaluación. \\ Palabras clave: accesibilidad web, ntc 5854, portal turístico, aplicativo web, criterios de verificación
}

\begin{abstract}
An accessibility inspection was carried out on a the tourism website, taking into account the four principles of NTC 5854 and in addition the minimum accessibility level guidelines, commonly known as conformance A, associated with these principles. For the development of the inspection, a set of minimum accessibility verification criteria was defined, and a web application was developed, which allows the evaluation of compliance with the defined criteria and obtains the statistical and graphic results of the evaluation.

key words: Web accessibility, NTC 5854, tourist portal, web application, verification criteria
\end{abstract}

\section{Introducción}

Con el crecimiento en el número de aplicaciones disponibles en la nube y con la gran cantidad de usuarios que pueden acceder a ellas, aspectos como la usabilidad y la accesibilidad pasan a ser fundamentales de cara a propiciar el desarrollo competitivo de las empresas del campo del desarrollo de software, así como garantizar el diseño inclusivo (Chanchí et al., - 2019, Chanchí et al., - 2020, Sánchez, 2011). Es así como la accesibilidad permite

\footnotetext{
1 Profesor. Programa Ingeniería de Sistemas, Facultad de Ingeniería. Universidad de Cartagena. gchanchig@unicartagena.edu.co 2 Profesor. Programa Ingeniería de Sistemas. Facultad de Ingeniería. Universidad de Cartagena. mospinaa@unicartagena.edu.co ${ }_{3}$ Profesor - Investigador. Facultad de Ingeniería y Ciencias Aplicadas. Universidad de las Américas. jorge.perez.medina@udla.edu.ec
} 
a las empresas del campo del desarrollo de software ampliar el enfoque de sus productos más allá de los usuarios promedio, abordando usuarios con limitaciones físicas, cognitiva y tecnológicas (Idrobo et al., -).

Aunque existen varias definiciones de accesibilidad, este artículo toma en consideración la definición de la ISO 26800, la cual se define como la medida en la que un producto software puede ser utilizado por personas de una población con la más amplia gama de características y capacidades para lograr un objetivo específico en un contexto específico de uso (ISO, 2011). De este modo, la vinculación de características de accesibilidad a un producto software permite que diferentes tipos de usuario puedan percibir, entender e interactuar con un producto software, de manera independiente a su diversidad funcional o contexto tecnológico de uso (NaranjoVillota et al., 2020).

En el contexto colombiano, en 2011 el Instituto Colombiano de Normas Técnicas (ICONTEC) publicó la norma NTC 5854, la cual define un conjunto de principios (perceptible, operable, comprensible y robusto), pautas y niveles de conformidad (A, AA, AAAA) para accesibilidad en aplicaciones web. La norma NTC 5854 pretende que el contenido de la web pueda ser accedido de manera independiente a las limitaciones tecnológicas e incluyendo a personas con diferentes diversidades funcionales, permitiendo que estas puedan entender, navegar e interactuar con los contenidos de la web (Nates \& Romero, (2018), Aguirre \& Abadía, (2017), Pérez-Oliveros et al., (2018).

En el principio perceptible, la información presente en las diferentes páginas de un portal web debe presentarse de tal manera que los diferentes usuarios puedan interpretarla. En el principio operable, la navegación debe ser intuitiva y los diferentes componentes del portal deben ser operados de manera adecuada desde el teclado. En lo referente al principio comprensible, la información presentada y su disposición deben ser fáciles de entender para el usuario. Finalmente, el principio robusto se enfoca en que los contenidos del portal web puedan ser interpretados y consumidos desde diferentes aplicaciones de usuario. Cada uno de los principios de accesibilidad incluyen un conjunto de pautas que han sido clasificadas en tres niveles de conformidad: mínimamente accesible (A), medianamente accesible (AA) y totalmente accesible (AAA). Estos niveles buscan orientar a los desarrolladores en cuanto al grado en el que un portal web cumple con los principios de accesibilidad de la norma (Revilla \& Carreras, 2018).

Considerando el impacto comercial y la importancia de usar contenidos web para la promoción del turismo (LunaNevarez \& Hyman, 2012; Agag \& El-Masry, 2017) y teniendo en cuenta que desde la temática de la accesibilidad es posible ampliar el número de usuario que pueden acceder a este tipo de contenidos, en este artículo se realiza una inspección del cumplimiento del nivel de accesibilidad mínima sobre el portal del Instituto de Cultura y Turismo del departamento de Bolívar - Colombia (Icultur) ${ }^{1}$, el cual es uno de los principales sitios encargados de promover la cultura y el turismo en los diferentes municipios del departamento de Bolívar. El objetivo de la inspección es determinar los aspectos que pueden ser mejorados dentro del portal web, con el fin de garantizar la accesibilidad mínima y por ende disminuir las barreras en el acceso a dichos contenidos de turismo a nivel tecnológico y por parte de personas con diferentes diversidades funcionales.

Teniendo en cuenta que no se ha evidenciado la existencia de una guía que permita orientar de manera clara el proceso de evaluación de aplicaciones web a partir de las pautas de la norma, en este trabajo se definieron un conjunto mínimo de criterios para verificar el cumplimiento de la accesibilidad en aplicaciones web. La elección de los criterios fue realizada pensando en un potencial interés y facilidades por parte de las empresas y

\footnotetext{
${ }^{1}$ Icultur - www.icultur.gov.co
} 
organizaciones de cara al cumplimiento de la ley de transparencia. Para conducir la inspección realizada en este artículo se desarrolló un aplicativo web que permite agilizar el estudio sobre la aplicación de turismo, facilitando el proceso de evaluación y el análisis estadístico de la inspección.

El resto del artículo está organizado de la siguiente forma: en la sección 2 se presenta la metodología empleada para el desarrollo del estudio; seguidamente, la sección 3 describe los criterios de verificación de accesibilidad mínima definidos; posteriormente, la sección 4 detalla el diseño y la implementación del aplicativo para el soporte a la inspección de la accesibilidad del portal web de Icultur; la sección 5 presenta los resultados obtenidos a partir de la ejecución de la inspección de accesibilidad mínima dentro del portal de Icultur; finalmente en la sección 6 se muestran las conclusiones y los trabajos futuros derivados de esta investigación.

\section{Metodología}

Para el desarrollo de la presente investigación, se consideraron 4 fases (ver Figura 1): (1) definición de criterios de verificación; (2) diseño e implementación de la herramienta de inspección; (3) estudio de caso y (4) análisis de resultados.

Figura 1

Metodología Considerada

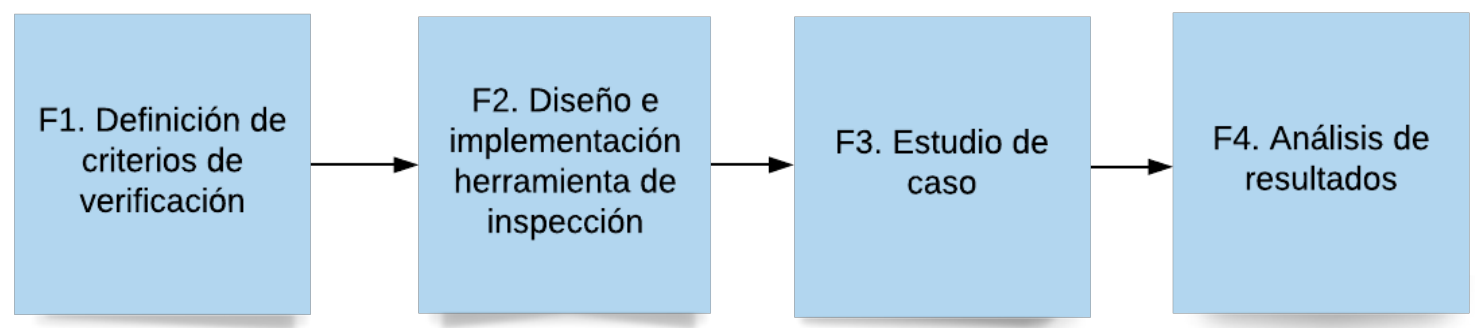

Fuente: Elaboración Propia

En la fase 1 se realizó la exploración de los diferentes principios, pautas y criterios de la norma NTC 5854, así como la definición de un conjunto de criterios de verificación para accesibilidad mínima (A) para cada principio de la norma. En la fase 2, se diseñó e implementó una herramienta web considerando los criterios de verificación previamente definidos. El aplicativo web tiene como objetivo soportar el proceso de evaluación del cumplimiento de los principios de accesibilidad y el análisis estadístico de la inspección. En la fase 3, se procedió con el proceso de la inspección de accesibilidad sobre el portal Icultur del departamento de Bolivar, con el fin de determinar los elementos básicos a mejorar para que dicho portal sea mínimamente accesible. Finalmente, en la fase 4 , a partir de los resultados estadísticos y gráficos de la evaluación proporcionados por la herramienta de inspección, se realizó el análisis del nivel de cumplimiento de cada uno de los principios de accesibilidad en el portal evaluado. Además, se obtuvieron un conjunto de recomendaciones para mejorar la accesibilidad del portal de Icultur.

\section{Resultados}

\subsection{Definición de los criterios de verificación}

Luego de explorar y analizar las diferentes pautas de la norma NTC 5854, en especial, las referentes al nivel de conformidad A (accesibilidad mínima), se procedió con la definición de un conjunto de criterios de verificación de accesibilidad en términos de preguntas, los cuales fueran útiles en la conducción de la inspección sobre el portal de Icultur. De este modo se definieron un total de 40 criterios de verificación distribuidos de la siguiente manera: perceptible (11 criterios), operable (14 criterios), comprensible ( 9 criterios) y robusto (6 criterios). A continuación, en la Tabla 1 se presenta un resumen de los criterios definidos, de tal manera que a modo de ejemplo se presentan un total de 3 criterios por cada principio. 
Tabla 1

Criterios de verificación de accesibilidad

\begin{tabular}{|c|c|}
\hline Principio & Criterios de verificación \\
\hline Preceptible & $\begin{array}{l}\text { ¿En qué medida los contenidos no textuales (audio, video, imágenes) están disponibles en forma de } \\
\text { texto? } \\
\text { ¿En qué medida las presentaciones visuales cuentan con un audio de descripción que permita } \\
\text { comprender el objetivo de estas? } \\
\text { ¿En caso de que el portal web cuente con sonido de fondo, en qué grado es posible pausar, detener o } \\
\text { cambiar el volumen del audio? }\end{array}$ \\
\hline Operable & $\begin{array}{l}\text { ¿En qué grado es posible navegar y operar toda la funcionalidad del sitio mediante el uso del teclado o } \\
\text { una interfaz de teclado? } \\
\text { ¿En qué medida es posible mover o quitar el foco de un componente usando el teclado o una interfaz } \\
\text { de teclado? } \\
\text { ¿En qué grado se ha evitado el uso de contenidos que destellen más de } 3 \text { veces por segundo? }\end{array}$ \\
\hline Comprensible & $\begin{array}{l}\text { ¿En qué medida se ha especificado en el lenguaje de marcado el idioma de las diferentes páginas del } \\
\text { sitio? } \\
\text { ¿En qué grado los reproductores de medios pueden mostrar los subtítulos de los contenidos de } \\
\text { manera correcta? } \\
\text { ¿En qué medida al detectar un error en la entrada de datos, es identificado y descrito al usuario } \\
\text { claramente? }\end{array}$ \\
\hline Robusto & $\begin{array}{l}\text { ¿En qué grado las etiquetas de marcado de las diferentes páginas web del sitio están completas } \\
\text { (etiqueta de apertura y cierre)? } \\
\text { ¿En qué medida se ha evitado el uso de atributos duplicados o con ID repetido en las etiquetas del } \\
\text { lenguaje de marcado? } \\
\text { ¿En qué grado las aplicaciones de usuario pueden interpretar y procesar el contenido de las páginas del } \\
\text { sitio de manera adecuada? }\end{array}$ \\
\hline
\end{tabular}

Fuente: Elaboración propia

\subsection{Herramienta de inspección desarrollada}

En esta sección se describe la estructura funcional y el desarrollo del aplicativo para la realización de inspecciones de accesibilidad mínima en sitios web. La Figura 2 presenta una arquitectura general del aplicativo web construido. Para su concepción se consideraron los criterios de verificación presentados en la Tabla 1.

Tal como se muestra en la Figura 2, el aplicativo para la inspección de accesibilidad está enmarcado dentro de un modelo de arquitectura cliente servidor. En el back-end se hizo uso del framework para microservicios Spark de Java, mientras que en el front-end se hizo uso de javascript y de la librería JQuery, así como de las librerías gráficas de javascript: canvasJS y chartJS. A nivel funcional, el módulo de evaluación de criterios usando Ajax solicita al back-end el listado de criterios, de tal manera que el módulo o servicio de carga de criterios obtiene el listado de criterios de verificación desde un archivo .csv y lo envía al front-end, en donde son desplegados por el módulo de evaluación de criterios. Así mismo, a través de este módulo el evaluador asigna una calificación entre 0 y 5 a cada uno de los criterios mínimos de accesibilidad. Al finalizar la evaluación de los criterios, el módulo de resultados hace uso del servicio o módulo de cálculos en el back-end, el cual se encarga de obtener el promedio de las evaluaciones realizadas a los diferentes criterios pertenecientes a los cuatro principios de accesibilidad. Los resultados de los cálculos son enviados al front-end y desplegados en la interfaz web. Una vez los resultados son presentados en el back-end, el evaluador puede generar un reporte tipo .csv con los resultados para lo cual se hace uso del módulo o servicio de reportes del back-end. De la misma forma, al tiempo que los resultados son presentados, se generan diferentes tipos de gráficas (barras, radiales, de área, de torta) con el análisis estadístico de los resultados obtenidos en la evaluación. Estas gráficas son generadas haciendo uso de la librería CanvasJS y ChartJS de Javascript. 
Figura 2

Diagrama de bloques del aplicativo

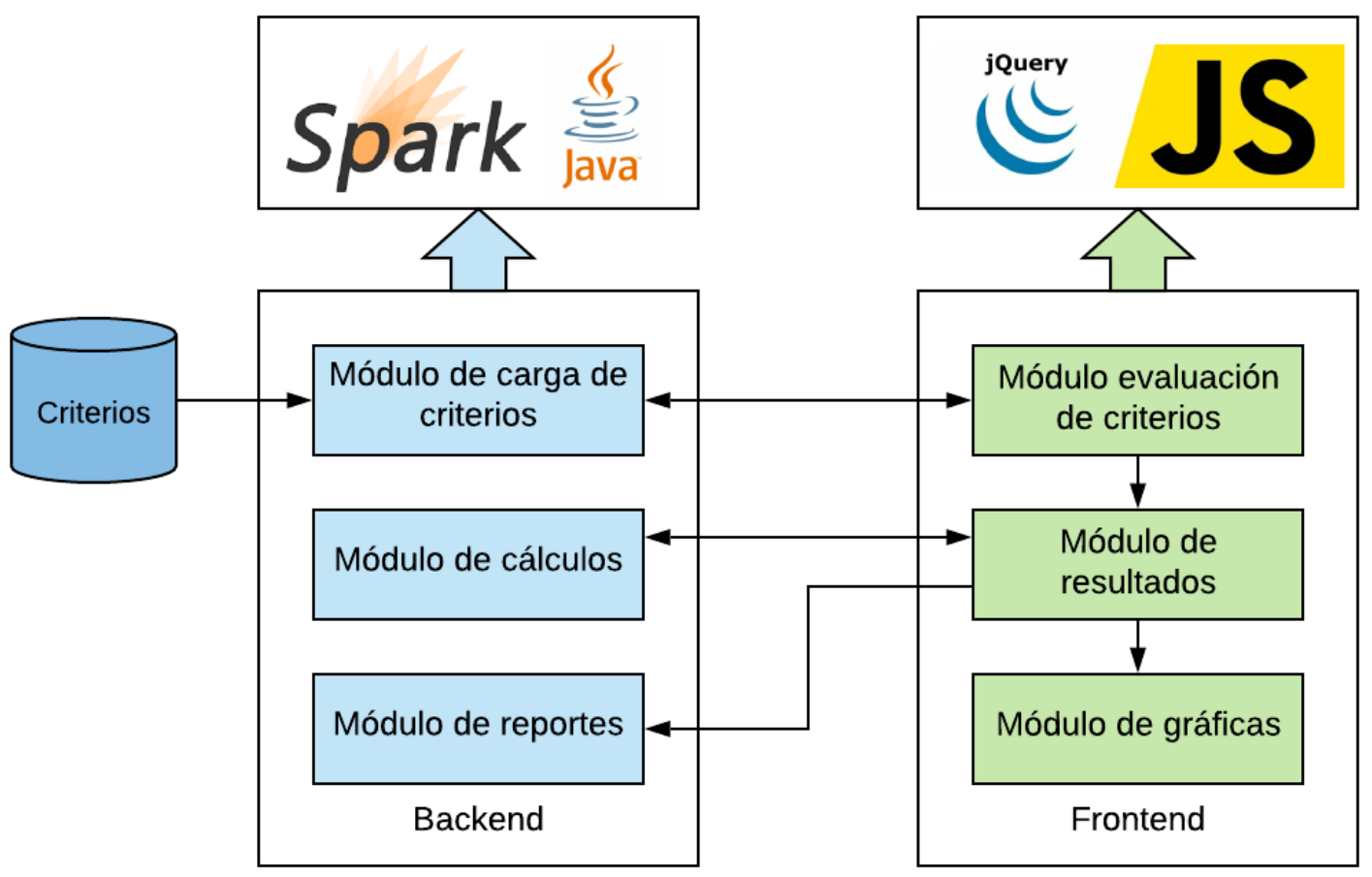

Fuente: elaboración propia

La Figura 3 muestra el diagrama de flujo del aplicativo web construido. En el diagrama se observa cómo una vez iniciado el aplicativo, los criterios de verificación de cada principio son cargados en la interfaz web. Una vez cargados los criterios, el evaluador procede a analizar manualmente su cumplimiento dentro del sitio web evaluado, asignando una calificación entre 0 y 5 que representa la medida en la que dicho criterio se cumple en el portal. Cuando la inspección por los diferentes principios y criterios ha terminado, el aplicativo web se encarga de mostrar el promedio obtenido en cada uno de los principios. Del mismo modo el evaluador puede generar un reporte a partir de los promedios obtenidos en cada uno de los principios de la norma. Finalmente, el aplicativo web permite generar 4 tipos de gráficas con los resultados de la evaluación: gráfica de barras, gráficas radiales, gráfica de área y gráfica de torta, las cuales desde diferentes perspectivas presentan el grado de cumplimiento de cada uno de los principios de la norma en el portal web evaluado.

A continuación, se presentan las interfaces gráficas definitivas del aplicativo web para la inspección de accesibilidad mínima en sitios web. La Figura 4 permite apreciar que la interfaz principal del aplicativo está conformada por 9 pestañas, las cuales pueden ser clasificadas en 3 grupos: pestañas de principios (Perceptible, Operable, Comprensible, Robusto), pestaña de resultados (Resultados) y pestañas de gráficas (Diagrama Barras, Diagrama Radial, Diagrama Porcentaje, Diagrama Torta). 
Figura 3

Diagrama de flujo del aplicativo

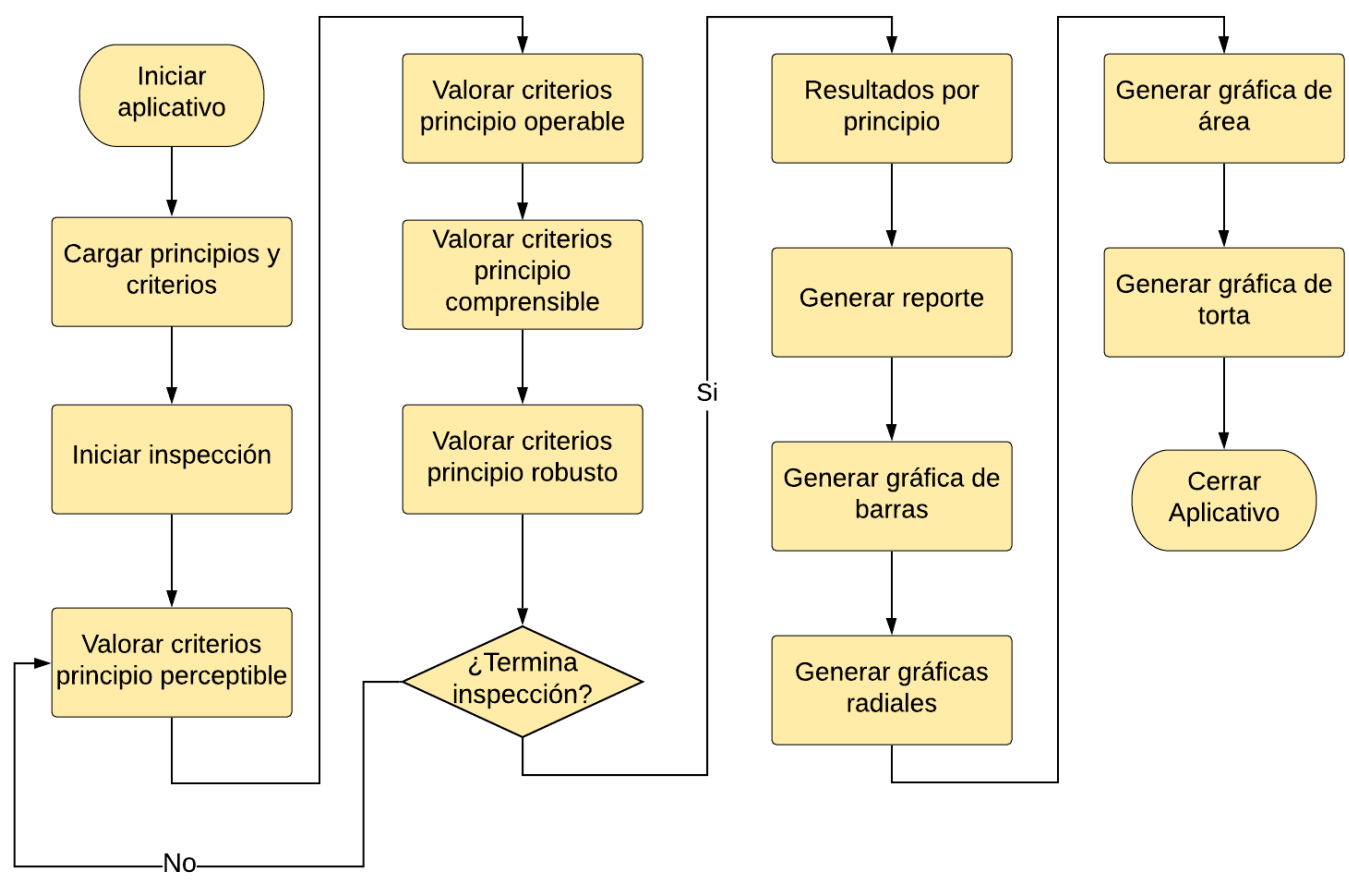

Fuente: Elaboración propia

En las pestañas de principios (cuatro primeras) se cargan los criterios asociados a cada uno de los principios de la norma NTC 5854 y el evaluador asigna una calificación entre 0 y 5 a cada uno de estos criterios dependiendo el grado de cumplimiento en el portal web. De manera alternativa, es posible asignar como calificación N/A, en caso de que un determinado criterio no se aplique dentro del sitio evaluado. Así a modo de ejemplo, se llenaron valores de prueba en las cuatro primeras pestañas con el fin de mostrar el funcionamiento del aplicativo.

Figura 4

Pestañas de principios

\section{Sistema de evaluación de accesibilidad - NTC 5854}

Evalúe cada uno de los criterios asociados a los 4 principios de la norma NTC 5854

Perceptible Operable Comprensible Robusto Resultados Diagrama Barras Diagrama Radial Diagrama Porcentaje Diagrama Torta

Principio Perceptible

\begin{tabular}{|l|l|l|}
\hline \multicolumn{1}{|c|}{ Id } & \multicolumn{1}{c|}{ Criterio } & \multicolumn{2}{c|}{ Valor } \\
\hline C1 & $\begin{array}{l}\text { ¿En qué medida los contenidos no textuales (audio, video, imágenes) está } \\
\text { disponible en forma de texto? }\end{array}$ \\
\hline C2 & $\begin{array}{l}\text { ¿En qué medida los contenidos de solo audio del portal cuentan con una alternativa } \\
\text { que presente información equivalente (texto, imágenes)? }\end{array}$ \\
\hline C3 & $\begin{array}{l}\text { ¿En qué grado los contenidos de solo video del portal cuentan con una alternativa } \\
\text { que presente información equivalente (texto, pista sonora, imágenes)? } \\
\text { ¿En qué grado los contenidos de video y las presentaciones multimedia del portal } \\
\text { web tienen subtítulos? }\end{array}$ \\
\hline C4 & & $\checkmark$ \\
\hline
\end{tabular}

Fuente: Elaboración propia

Al terminar el proceso de evaluación, el aplicativo web se encarga de presentar una tabla con los resultados obtenidos tras la evaluación de los criterios de verificación de accesibilidad mínima de cada principio (ver Figura 5). 
Figura 5

Pestañas de resultados

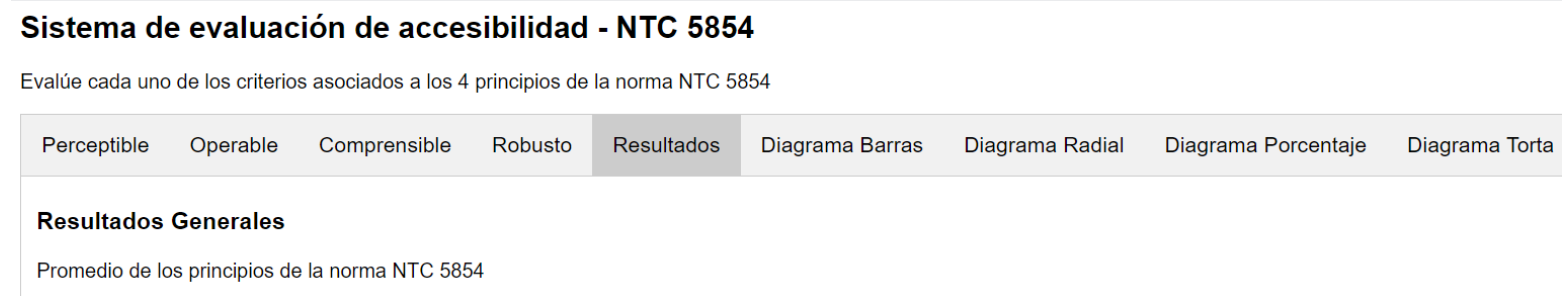

\begin{tabular}{|c|c|}
\hline Criterio & Valor \\
\hline Perceptible & 2 \\
\hline Operable & 2.143 \\
\hline Comprensible & 3.556 \\
\hline Robusto & 2 \\
\hline Promedio General & 2.425 \\
\hline
\end{tabular}

Reporte

Fuente: Elaboración propia

Así, a partir de los valores de prueba agregados a los diferentes criterios de los cuatro principios, se obtuvo que el principio que tiene un mayor promedio es el Comprensible con una calificación de 3.556, mientras que los principios que obtuvieron una menor valoración fueron Perceptible y Robusto con un promedio de 2. Así mismo, se obtuvo que el promedio general de la evaluación de los cuatro principios es de 2.425 . Finalmente, en la pestaña Resultados es posible generar un reporte .csv por princio y además de los promedios generales.

La Figura 6 presenta un ejemplo de una gráfica de barras generada mediante la opción "Diagrama Barras". Esta gráfica muestra el promedio obtenido en cada uno de los cuatro principios de la norma. Así, a partir de los valores de prueba asignados en las cuatro primeras pestañas, se obtuvo que el principio con una valoración promedio más alta es el Comprensible (P3) mientras que los principios con la valoración promedio más baja son Comprensible (P1) y Robusto (P4).

Figura 6

Pestaña de diagrama de barras

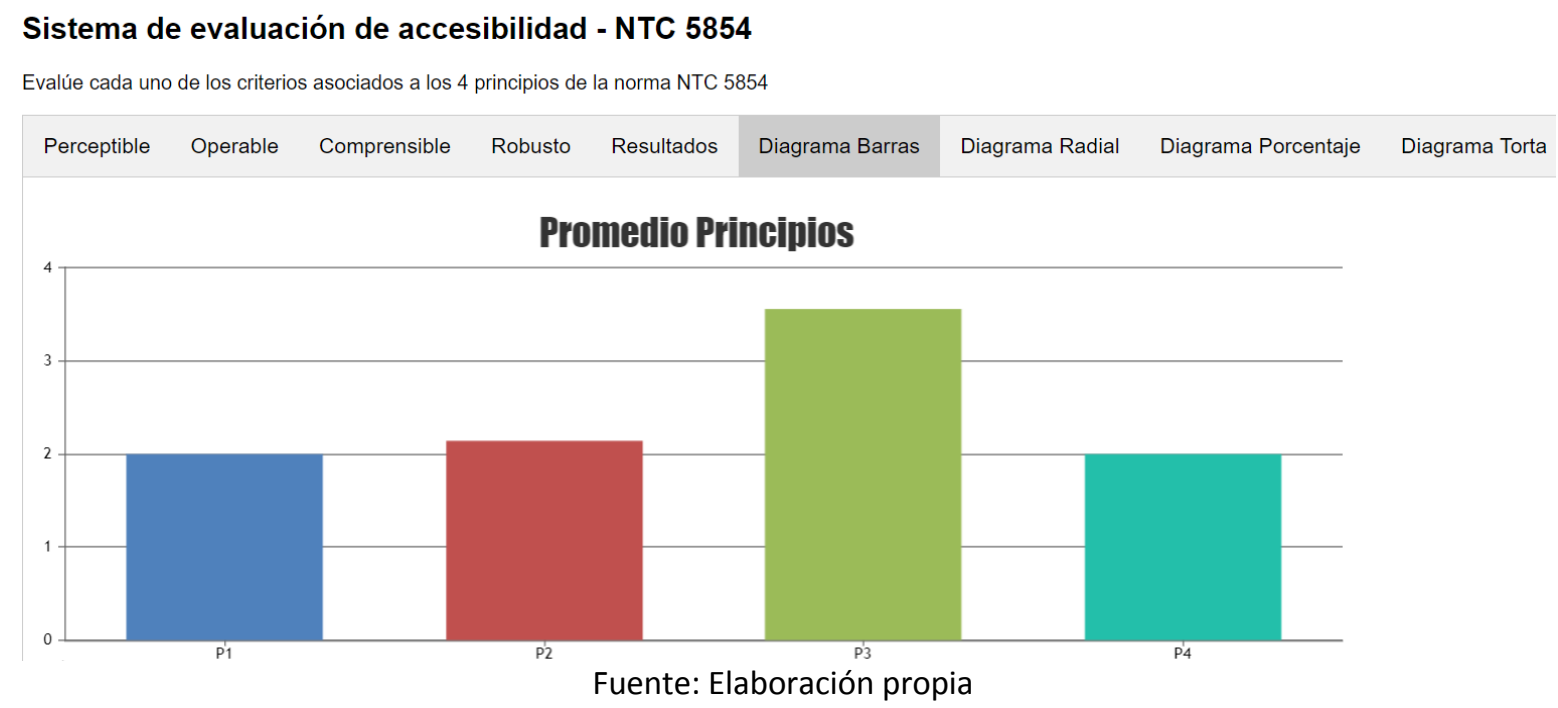

De forma semejante, en la Figura 7 se aprecia una de las gráficas radiales generadas en pestaña "Diagrama Radial". Esta gráfica representa la distribución de las distintas valoraciones obtenidas en cada uno de los criterios del principio Perceptible. 
Figura 7

Pestaña de diagrama radial

Sistema de evaluación de accesibilidad - NTC 5854

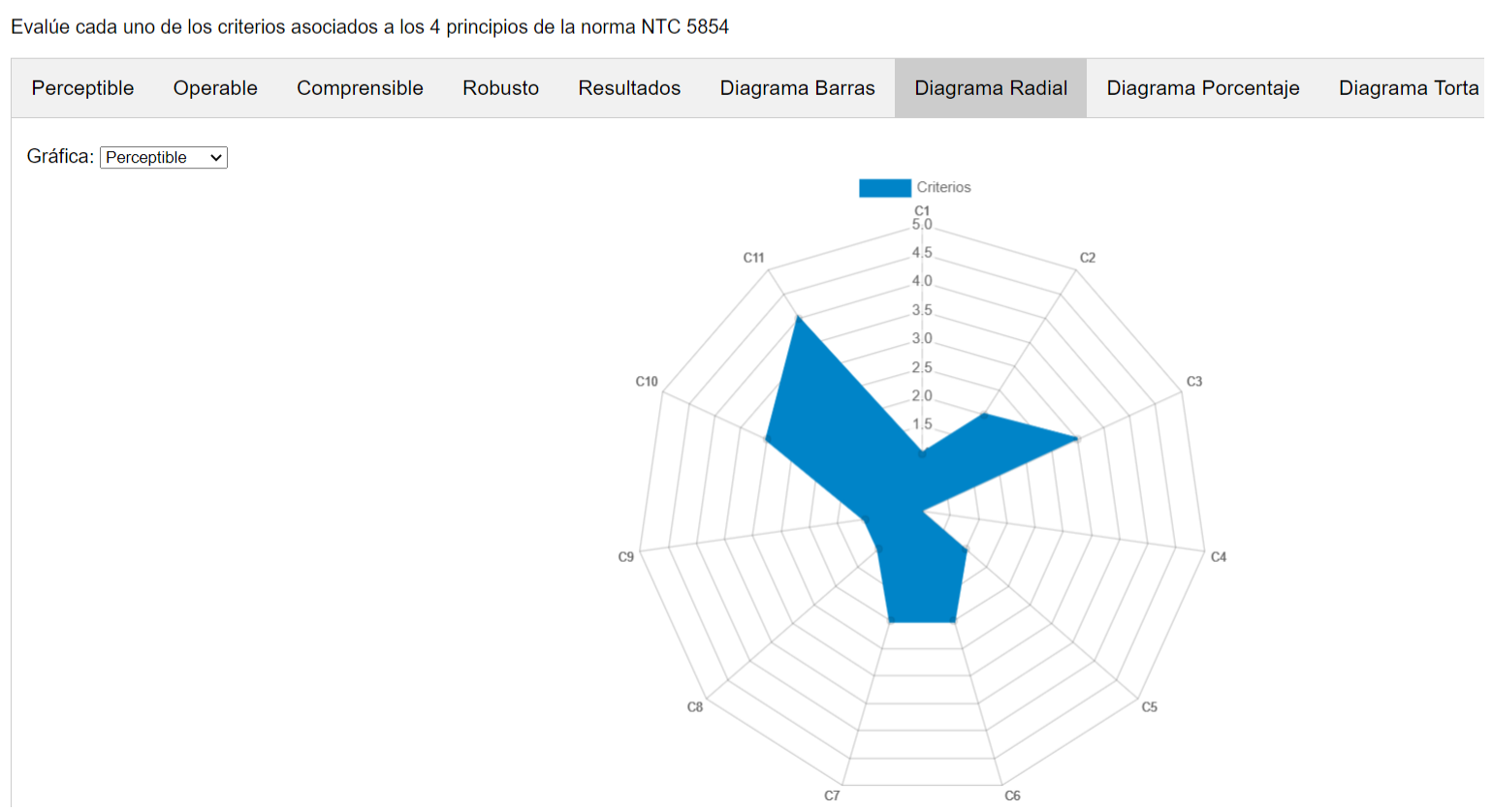

Fuente: Elaboración Propia

Se puede apreciar en la Figura 7 que, a partir de las valoraciones de prueba realizadas en la primera pestaña, el criterio con más alta valoración es el principio Perceptible C11 con un valor de 4.0. Del mismo modo, en esta pestaña es posible mediante la lista de selección de la parte superior izquierda, obtener las gráficas radiales para cada principio y un diagrama radial general.

Figura 8

Pestaña de diagrama porcentaje

Sistema de evaluación de accesibilidad - NTC 5854

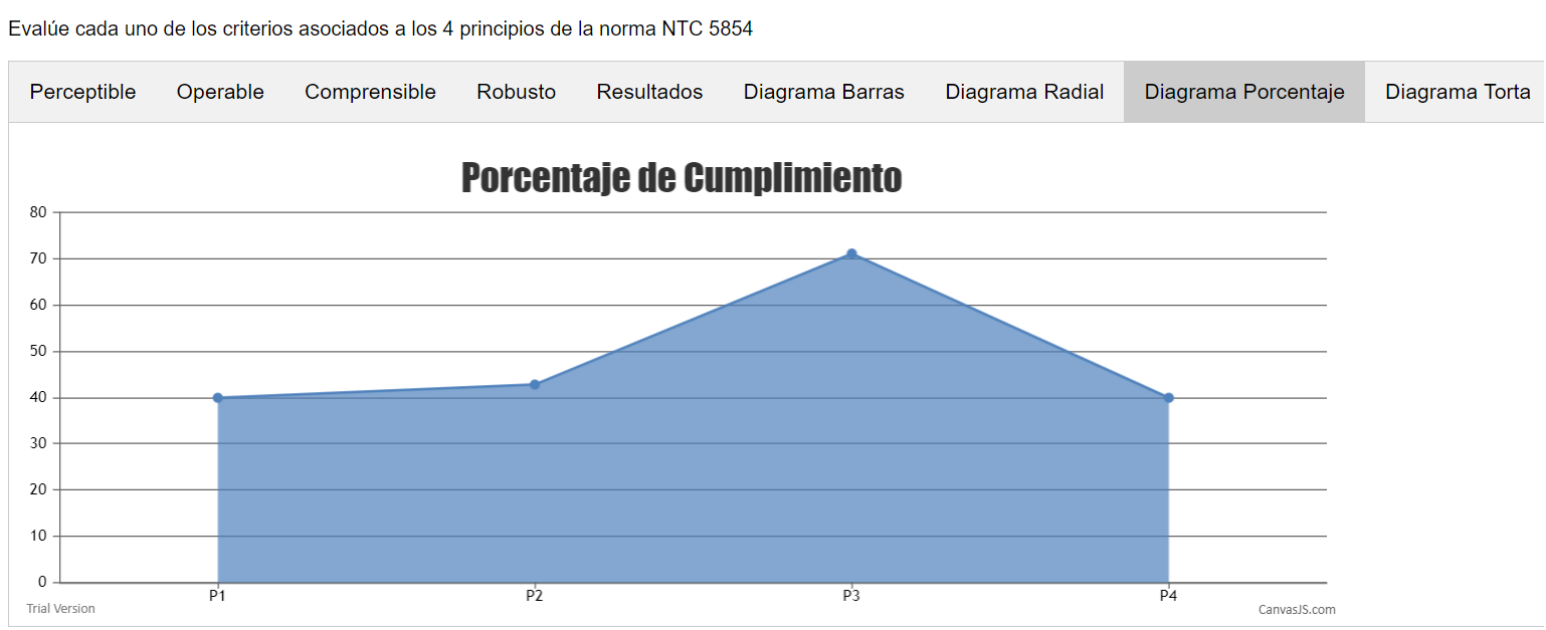

Fuente: Elaboración propia

En la Figura 8 se muestra la gráfica de área o de porcentajes generada en la pestaña "Diagrama Porcentaje", la cual representa el porcentaje de cumplimiento de los principios de la norma NTC 5854 dentro del aplicativo web evaluado. Se aprecia que, a partir de los valores de prueba proporcionados en las cuatro primeras pestañas, el porcentaje de cumplimiento más alto es el principio Comprensible (P3) con 70\%, mientras que los principios con un menor porcentaje de cumplimiento son Perceptible (P1) y Robusto (P4) con un $40 \%$. 
Finalmente, el aplicativo web desarrollado permite obtener en la pestaña "Diagrama de Torta", la distribución porcentual de los principios en el sitio evaluado, de tal modo que este diagrama muestra el o los principios que de acuerdo con su calificación tienen una mayor predominancia en el portal.

\subsection{Estudio de caso}

A partir de los criterios de verificación definidos, así como la herramienta de inspección propuesta, se procedió con la evaluación de la accesibilidad mínima dentro del portal Icultur, el cual se encarga de promover y difundir la cultura y el turismo en el departamento de Bolívar (ver Figura 9).

Figura 9

Portal web Icultur

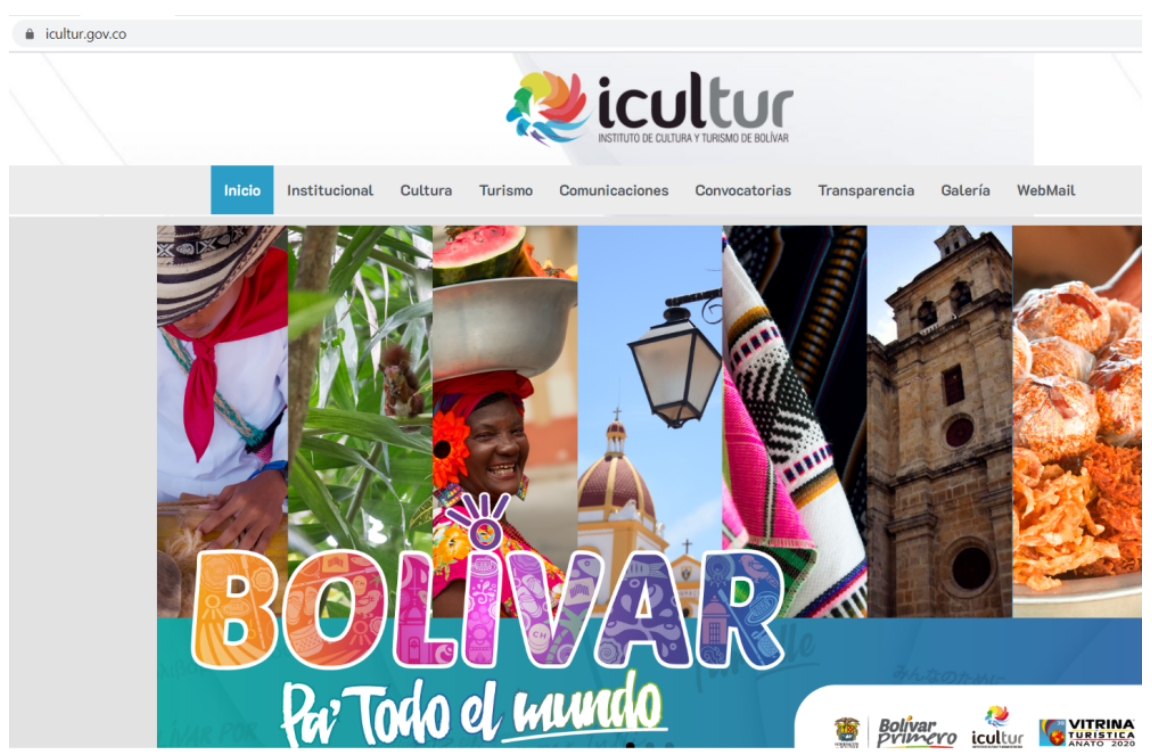

Fuente: Icultur - www.icultur.gov.co

Así, una vez ejecutada la inspección sobre el sitio de Icultur, la herramienta obtuvo los resultados presentados en la Tabla 2 para cada uno de los principios de la norma NTC 5854. De este modo, se puede apreciar que el principio que mejor se cumplió en el portal web Icultur fue el principio Robusto con una calificación promedio en sus criterios de 3.833, mientras que el principio que se cumplió en menor medida fue el Perceptible con una calificación promedio en sus criterios de 2.429. Del mismo modo se aprecia que 3 de los 4 principios están por debajo de 3.0 y el promedio general de la accesibilidad es de 2.953 , por lo que el nivel de cumplimiento de la accesibilidad mínima es regular.

Tabla 2

Resultados de la Inspección de accesibilidad

\begin{tabular}{|c|c|c|c|c|}
\hline Perceptible & Operable & Comprensible & Robusto & Promedio General \\
\hline 2.429 & 2.923 & 2.625 & 3.833 & 2.953 \\
\hline
\end{tabular}

Fuente: Elaboración propia

La Figura 10 contrasta los resultados presentados en la Tabla 2. Se puede observar como el principio Robusto es el que abarca una mayor área en el diagrama, mientras que el principio Perceptible es el que menos área abarca en el mismo diagrama. Lo anterior representa que el portal web evaluado se puede consumir de manera adecuada desde los dispositivos de usuario final, pero requiere adaptar la información presentada a diferentes perfiles de uso. 
Figura 10

Diagrama radial principios del caso de estudio

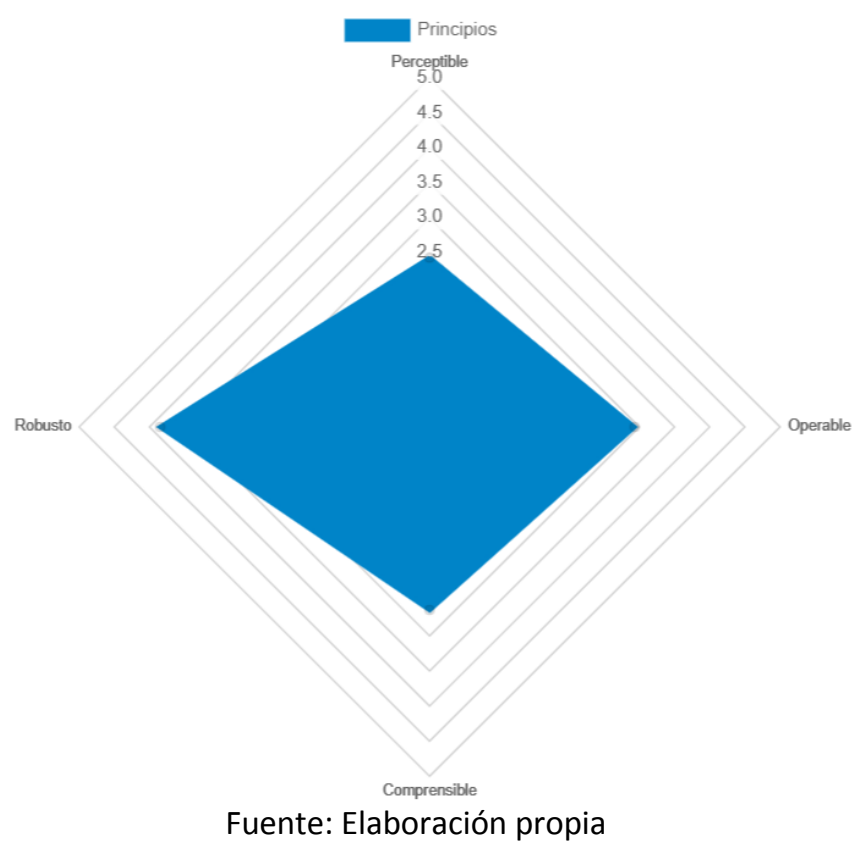

En la Figura 11 se presenta el diagrama de porcentajes generado por la herramienta de inspección, donde se aprecia que el principio Perceptible tiene un porcentaje de cumplimiento del $48.58 \%$, el principio Operable un porcentaje de cumplimiento del $58.46 \%$, el principio Comprensible un porcentaje de cumplimiento del $52.5 \%$ y finalmente el principio Robusto con un porcentaje de cumplimiento del $76.66 \%$.

Figura 11

Diagrama de porcentaje del caso de estudio Sistema de evaluación de accesibilidad - NTC 5854

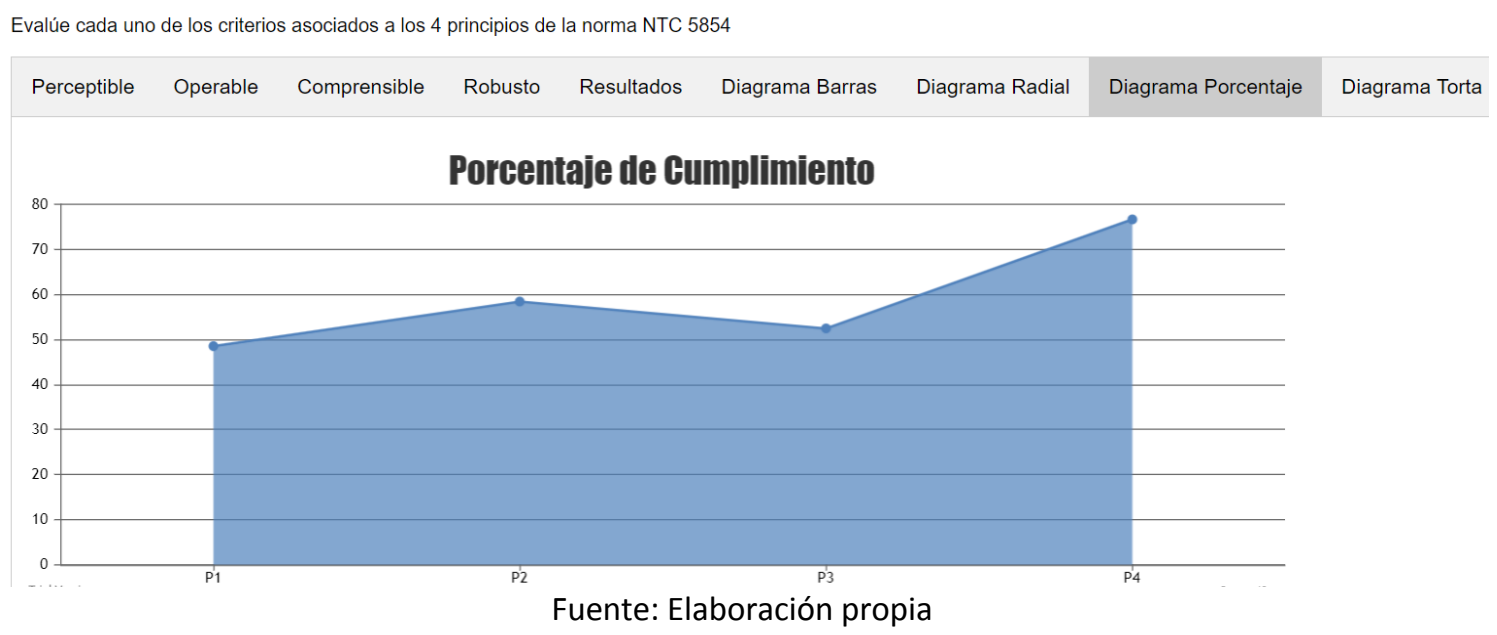

Apartir de los resultados y el análisis realizado por la herramienta de inspección se puede decir que: en cuanto al principio Perceptible es adecuado que el portal haga uso de información alternativa referente a las imágenes y presentaciones multimedia de los sitios turísticos. En lo concerniente al principio Robusto el portal hace uso de tecnologías convencionales y es desplegado de manera adecuada en dispositivos móviles. Del mismo modo a nivel general el porcentaje de cumplimiento de la accesibilidad mínima es del $59.06 \%$, por lo que se puede concluir que el nivel de accesibilidad mínima en el portal de Icultur es regular. Finalmente, en la Tabla 3 se 
presentan las recomendaciones obtenidas para cada uno de los principios de accesibilidad dentro del portal web de turismo evaluado.

Tabla 3

Recomendaciones obtenidas

\begin{tabular}{|c|c|}
\hline Principio & Recomendación \\
\hline Perceptible & $\begin{array}{l}\text { Se recomienda incluir un texto alternativo a las diferentes imágenes presentes en el sitio. Se sugiere } \\
\text { evitar el uso de imágenes de texto en las diferentes páginas del sitio. } \\
\text { Se recomienda incluir una audio-descripción para las presentaciones multimedia de los sitios turísticos } \\
\text { disponibles en el menú "Galería". } \\
\text { Se recomienda incluir subtítulos a las presentaciones multimedia de sitios turísticos disponibles en el } \\
\text { sitio (menú "Turismo" y menú "Galería"). } \\
\text { Se sugiere evitar que los componentes funcionales indiquen acciones que dependan de la forma, el } \\
\text { tamaño, el color o la ubicación (Ej. Clic aquí). }\end{array}$ \\
\hline Operable & $\begin{array}{l}\text { Aunque es posible navegar por el sitio con el teclado, el foco se pierde en el carrusel de imágenes de la } \\
\text { página de inicio. Se sugiere mejorar el mecanismo de navegación por la página principal y aquellas que } \\
\text { hacen uso de carrusel de imágenes. } \\
\text { Se recomienda incluir la opción de quitar el foco de un componente seleccionado al momento de navegar } \\
\text { con el teclado. } \\
\text { Se recomienda incluir las opciones para pausar, reanudar y/o extender el tiempo dentro de los carruseles } \\
\text { de imágenes dentro del portal de turismo (pestañas "Inicio" y “Galería"), de tal modo que el usuario } \\
\text { pueda visualizar la información de manera adecuada. } \\
\text { Se recomienda incluir un título en las diferentes páginas del sitio web, el cual describa de manera } \\
\text { adecuada el propósito del contenido presentado en cada página. } \\
\text { Se recomienda incluir la ruta de miga de pan en las diferentes páginas del portal, con el fin de orientar } \\
\text { mejor al usuario. } \\
\text { Dado que la página cuenta con muchas imágenes con hipervínculos se sugiere incluir en cada una de } \\
\text { ellas una descripción al ubicar el foco o pasar el ratón sobre ellas. }\end{array}$ \\
\hline Comprensible & $\begin{array}{l}\text { Para evitar confusiones en la navegación se sugiere evitar que al pasar el ratón por el menú se muestren } \\
\text { las opciones. } \\
\text { Se recomienda que el menú superior mantenga la consistencia en la disposición al acceder a la opción } \\
\text { "Turismo" del menú principal. } \\
\text { Se recomienda que, al momento de presentar las diferentes imágenes del carrusel, se vaya mostrando } \\
\text { la información de los sitios turísticos mostrados en las imágenes. } \\
\text { Se sugiere que los errores en las entradas de los formularios sean detectados antes de enviar la petición } \\
\text { (Ej. Menú de servicio al ciudadano). } \\
\text { Se recomienda que los formularios incluyan instrucciones sobre el tipo de datos a ingresar en los } \\
\text { diferentes campos (numérico, texto, numérico sin puntos, etc). } \\
\text { Se sugiere incluir información sobre los campos obligatorios e incluir la validación en el diligenciamiento } \\
\text { de dichos campos (Ej. El campo de mensajes en el formulario de preguntas, quejas y reclamos del menú } \\
\text { servicio al ciudadano). }\end{array}$ \\
\hline Robus & $\begin{array}{l}\text { Se recomiendo hacer uso de un validador de html para corregir las etiquetas html que no están } \\
\text { completas y los ids repetidos. }\end{array}$ \\
\hline
\end{tabular}

Fuente: Elaboración propia

\section{Conclusiones}

La vinculación de la accesibilidad en portales web como los turísticos, permite ampliar el número de usuarios potenciales que pueden acceder e interactuar con la información de sitios y lugares de interés de diferentes latitudes, de manera independiente al contexto tecnológico de uso y a las limitaciones de los usuarios.

De cara a facilitar la inspección de accesibilidad sobre el portal turístico de Icultur, en este artículo se propuso como aporte un conjunto de criterios para la verificación de la accesibilidad mínima de acuerdo con la norma 
NTC 5854, los cuales fueron utilizados para determinar el nivel de cumplimiento de los principios de accesibilidad en el portal de Icultur en cuanto al nivel de conformidad $A$.

A partir de los criterios de verificación definidos en este trabajo, se construyó con el framework Spark de Java un aplicativo web para la inspección de accesibilidad mínima en sitios web, el cual permite realizar la evaluación y análisis estadístico de los resultados obtenidos. Esta herramienta tiene como aporte la generación de gráficos radiales, de área y de barras, los cuales permiten visualizar de manera más clara el nivel de cumplimiento de la accesibilidad mínima por principio y criterio.

Como resultado de la inspección, se obtuvo que el principio que se cumple en mayor medida es el Robusto, teniendo en cuenta que el sitio web hace uso de herramientas convencionales y cuenta con un diseño responsivo (adaptativo). Del mismo modo el principio que se cumple en menor medida es el Perceptible, dado que es necesario dotar las presentaciones multimedia y a las imágenes de los sitios de interés de información alternativa en formato de texto y/o audio.

Como trabajo futuro derivado de la presente investigación, se espera extender el estudio de accesibilidad a otras organizaciones no gubernamentales promotoras del turismo, así como a diferentes páginas gubernamentales del departamento de Bolívar y la ciudad de Cartagena de Indias.

\section{Referencias bibliográficas}

Agag, G. M., \& El-Masry, A. A. (2017). Why Do Consumers Trust Online Travel Websites? Drivers and Outcomes of Consumer Trust toward Online Travel Websites. Journal of Travel Research, 56(3), 347-369. https://doi.org/10.1177/0047287516643185

Aguirre, D., \& Abadía, I. (2017). Review of accessibility and usability guidelines for website design for the elderly people. Sistemas y Telemática, 15 (42), 9-29.

Chanchí, G., Acosta-Vargas, P., \& Campo, W. (2019). Construcción de recursos educativos para la temática de accesibilidad en el curso de interacción humano computador. RISTI - Revista Ibérica de Sistemas e Tecnologias de Informação, (E23), 171-183.

Chanchí, G., Gómez, M., \& Campo, W. (2020). Criterios de usabilidad para el diseño e implementación de videojuegos. RISTI - Revista Ibérica de Sistemas e Tecnologias de Informação (E26), 461-474.

Idrobo, C., Idrobo, M., Chanchí, G., \& Vidal, M. (2017). Accesibility Guide for the Design and Implementation of Websites According to the NTC 5854 Standard. Communications in Computer and Information Science, 572-585.

ISO. (2011). ISO 26800:2011(en). Obtenido de International Organization for Standardization: https://www.iso.org/obp/ui/\#iso:std:iso:26800:ed-1:v1:en

Luna-Nevarez, C., \& Hyman, M. R. (2012). Common practices in destination website design. Journal of destination marketing \& management, 1(1-2), 94-106.

Naranjo-Villota, D., Guaña-Moya, J., Acosta-Vargas, P., \& Muirragui-Irrazábal, V. (2020). Evaluación de la accesibilidad web en institutos acreditados de educación superior del Ecuador. Revista Espacios, 41(4), 519.

Nates, A., \& Romero, J. (2018). Sistematización del desarrollo y adaptación de sitios web ajustados a la norma NTC 5854. Bogotá-Colombia: Universidad Distrital Francisco José de Caldas. 
Pérez-Oliveros, D., Vidal, M., \& Chanchí, G. (2018). Identifcación de problemas de accesibilidad en juegos serios. Revista Colombiana de Computación, 19(2), 24-36.

Revilla, O., \& Carreras, O. (2018). Accesibilidad Web - WCAG 2.1 de forma sencilla. Madrid-España: Itakora Press.

Sánchez, W. (2011). La usabilidad en ingeniería de software: definición y características. Ing-novación, 7-21.

Esta obra está bajo una Licencia Creative Commons

Attribución-NoCommercial 4.0 International

\section{(cc) EYY-NC}

